\title{
LAMINOPLASTY FOR THE SURGICAL TREATMENT OF VARIOUS SPINAL CANAL PATHOLOGIES
}

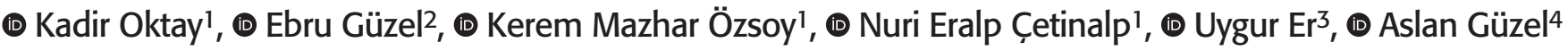 \\ ${ }^{1}$ Çukurova University Faculty of Medicine, Department of Neurosurgery, Adana, Turkey \\ ${ }^{2}$ Gaziantep Medical Park Hospital, Clinic of Radiology, Gaziantep, Turkey \\ ${ }^{3}$ Düzce University Faculty of Medicine, Department of Neurosurgery, Düzce, Turkey \\ ${ }^{4}$ Bahçeşehir University Faculty of Medicine, Department of Neurosurgery, İstanbul, Turkey
}

\begin{abstract}
Objective: It was aimed to evaluate the patients who underwent laminoplasty for the various pathologies that were located in the spinal canal. Materials and Methods: The records of the patients who underwent osteoplastic laminoplasty for various pathologies between 2014 and 2019 were analyzed retrospectively. Patient data including age, gender, preoperative and postoperative neurological conditions, type and radiographic localization of their pathologies, preoperative and postoperative deformities, involved segments, hospitalization periods and postoperative complications were gathered.

Results: Sixty-two patients were included in the study. The mean age of the patients was 44.3 years (9-80 years). Fifty-two patients had tumoral and 10 patients had non-tumoral pathologies. Grade 3 and 4 patients were predominant in the preoperative period, while grade 1 and 2 patients were predominant in the postoperative period according to Modified McCormick Scale classification of the patients. Twenty-three patients had preoperative deformity. A total of 138 laminae were reconstructed. One patient had cerebrospinal fluid leak in the long-term period and 1 patient had quadriplegia and respiratory deficiency in the postoperative period. In only 1 patient, a new-onset deformity developed and in 1 patient, progression of previous deformity was seen. However, the deformities of these patients did not require corrective surgery.

Conclusion: Laminoplasty technique has recently gained popularity and begun to replace traditional laminectomy technique. Laminoplasty is a preferred technique with the low complication rates and high patient-comfort in the postoperative period.

Keywords: Laminoplasty, spinal tumor, spinal deformity, cerebrospinal fluid leak
\end{abstract}

\section{INTRODUCTION}

Posterior approaches are the most appropriate and most commonly used methods in the surgery of lesions located in the spinal canal. Because they are easy ways to enter and widen the canal via laminae. The main purpose in these operations; to obtain adequate exposure and manipulation view and to provide adequate decompression. When performing these procedures, it should be the main goal of maintaining spinal stability by applying a minimal anatomic approach as much as possible ${ }^{(1,2)}$. However, opening an insufficient bone window may increase the complications of the surgery.

Laminectomies have been applied widely for many years for this purpose. However, due to the reasons such as the development of instability, occurence of granulation tissue, loss of normal anatomic plan and high rate of complications in reoperations, new approaches have been sought ${ }^{(3)}$. Laminoplasty techniques are now widely accepted procedures instead of laminectomy. In the present study, it is aimed to evaluate 62 patients who underwent laminoplasty due to various pathologies that are located in the spinal canal.

\section{MATERIALS AND METHODS}

The records of the patients who underwent osteoplastic laminoplasty for various pathologies in a single institution, between 2014 and 2019 were retrospectively reviewed. All study protocols were performed in accordance with the ethical rules proposed in the Helsinki Declaration. Ethics committee approval was received from Çukurova University Non-Interventional Scientific Research Ethics Committee (11.06.2021-112). Sixty-two patients who underwent laminoplasty with posterior approach were included in the study. Patient records including age, gender, preoperative and

Address for Correspondence: Kadir Oktay, Çukurova University Faculty of Medicine, Department of Neurosurgery, Adana, Turkey Phone: +90 5062565176 E-mail: drkadiroktay@hotmail.com Received: 17.10.2021 Accepted: 01.11.2021

ORCID ID: orcid.org/0000-0003-2420-2734 
postoperative neurological conditions, type and radiographic localization of their pathologies, preoperative and postoperative deformities, involved segments, hospitalization periods and postoperative complications were gathered.

Surgical planning was performed according to the location of the lesions. Spinal contrast-enhanced magnetic resonance imaging (MRI) of all of the patients was performed preoperatively (Figure 1). Anteroposterior and lateral radiographs of the patients were performed. Hyperflexion and hyperextension radiographs were added in the patients with the suspicion of instability. Laminoplasty was not applied to the patients with preoperative instability and malalignment. New-onset or worsening of preoperative deformities were evaluated including loss of cervical or lumbar lordosis, cervical or thoracic kyphosis greater than $10^{\circ}$ and scoliosis. All patients underwent a posterior approach in prone position. The laminae were cut bilaterally using a high-speed drill. Laminoplasty flaps were in the form of osteoplastic flaps and all segments were adhered to each other (Figure 2). Watertight closure of the duramater was ensured in all of the patients who had intradural pathologies. The laminoplasty flaps were fixed to their original position by using miniplates. For each lamina, 2 miniplates and 4 miniscrews were used. In all patients, Jackson-Pratt drains were placed above the laminae. During the drilling of the laminoplasty flaps, injuries of duramater or nerve roots had not been developed. The patients were medicated with prophylactic antibiotherapy (ampicillin sulbactam) peroperatively and postoperatively for

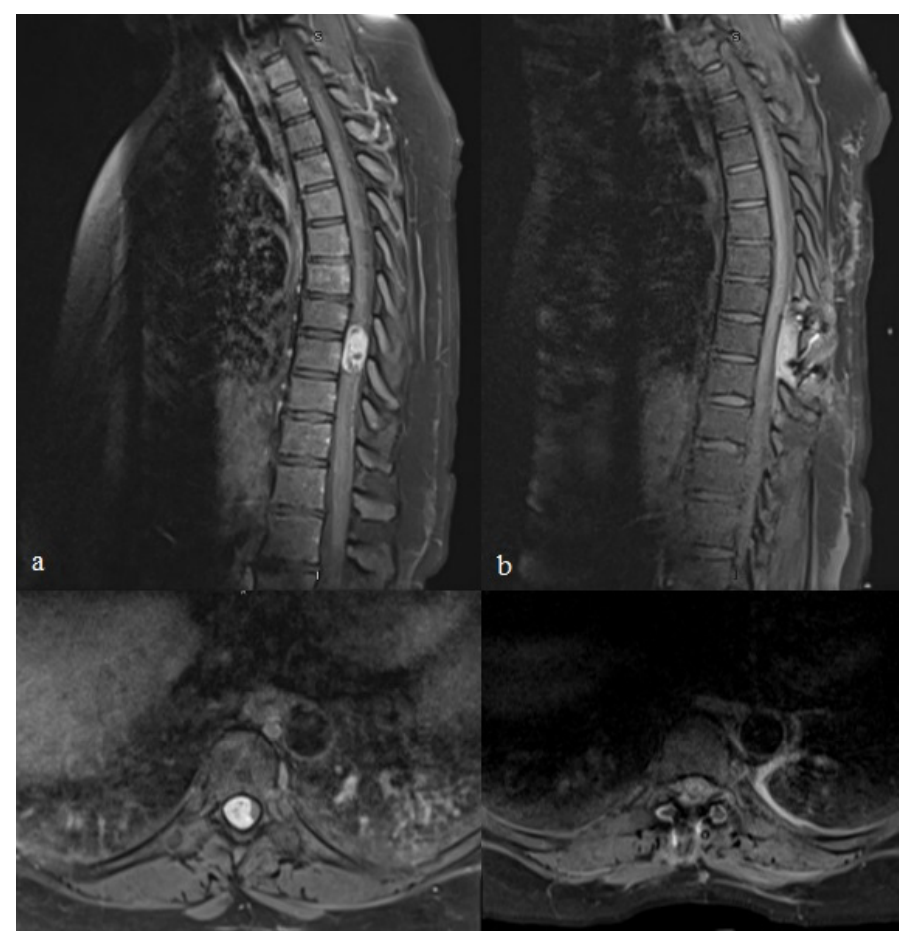

Figure 1. a) Preoperative sagittal and axial contrast-enhanced magnetic resonance images of 48-year-old female patient with T8-T9 intradural-extramedullary localized schwannoma. b) Postoperative sagittal and axial contrast-enhanced magnetic resonance images of the same patient revealing total resection of the tumor
1 day. Modified McCormick Scale (MMS) was used to evaluate preoperative and postoperative neurological conditions of the patients. In the postoperative period, spinal contrast-enhanced MRI were performed in order to evaluate the lesions and operation areas and hyperflexion-hyperextension radiographs were performed in order to check for the development of instability (Figure 3).

\section{Statistical Analysis}

SPSS 25.0 (IBM Corporation, Armonk, New York, United States) program was used to analyze the variables. The Mann-Whitney

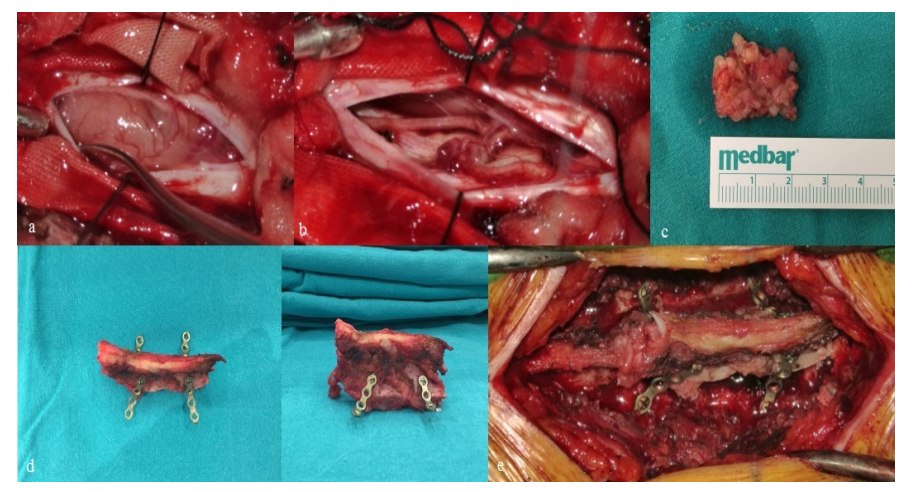

Figure 2. a) Peroperative image of the same patient revealing the intradural-extramedullary tumor. b) Peroperative image revealing total resection of the tumor. c) Image of the resected tumor. d) Peroperative image of the laminoplasty flap. e) Peroperative image revealing the fixation of the laminoplasty flap with miniplates

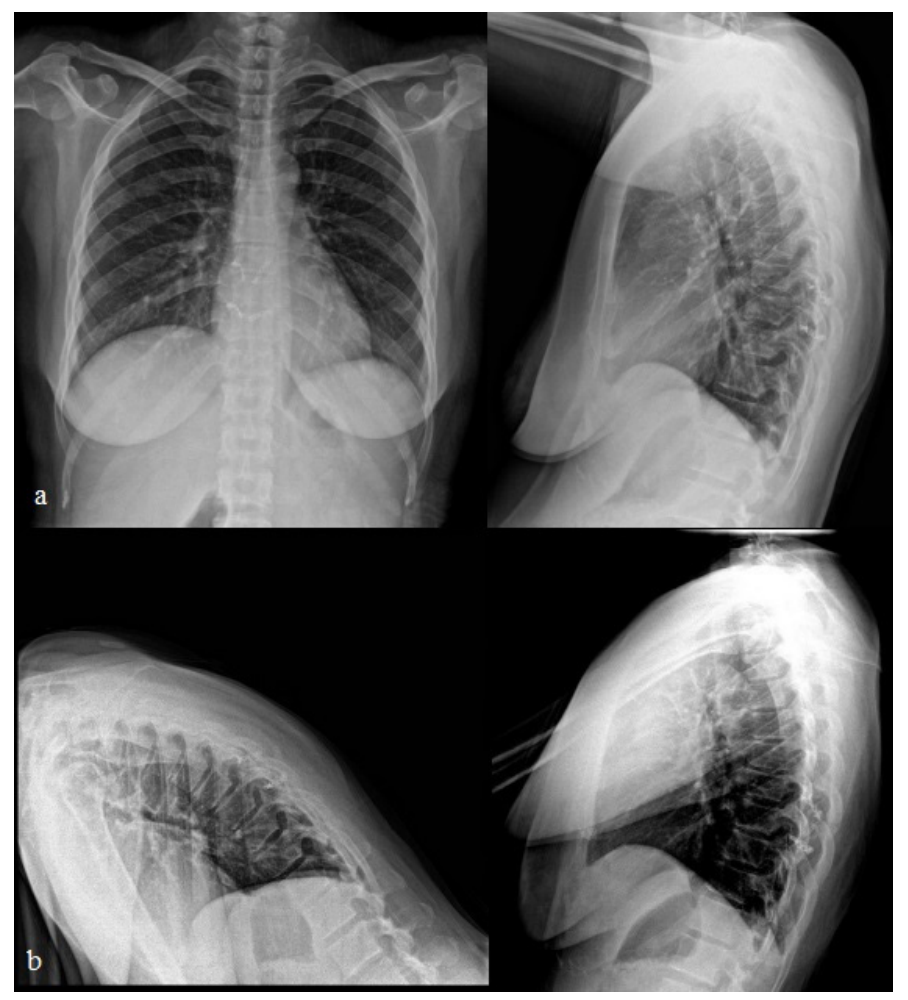

Figure 3. a) Postoperative 2-years anteroposterior and lateral radiographs of the same patient. b) Postoperative 2-years hyperflexion and hyperextension radiographs showing no kyphosis or instability 
turkishspine

$\mathrm{U}$ test was used with the Monte Carlo results to compare the categorical variables quantitatively. The quantitative variables were described as mean \pm standard deviation, and the median range (maximum-minimum), and categorical variables as $n$ (\%). The variables were examined at $95 \%$ confidence level and $\mathrm{p}<0.05$ was considered significant.

\section{RESULTS}

\section{Patient Profile}

A total of 62 patients were included in the study. The mean age of the patients was 44.3 years ( $9-80$ years). Thirty-seven patients (59.6\%) were female and 25 patients (40.4\%) were male. Two patients were in pediatric age group and 60 were adult. Fifty-two patients had tumoral lesions and 10 patients had non-tumoral pathologies. Of these 10 patients, 3 had arteriovenous malformation, 3 had cavernous malformation, 3 had spinal abscess and 1 had arachnoid cyst. In the tumoral group, 14 patients had schwannoma, 13 patients had ependymoma, 12 patients had meningioma, 5 patients had astrocytoma, 3 patients had lipomatosis, 2 patients had metastasis, 1 patient had hemangioendothelioma, 1 patient had primitive neuroectodermal tumor and 1 patient had epidermoid tumor (Table 1). Grade 3 and 4 patients were predominant in the preoperative period, while grade 1 and 2 patients were predominant in the postoperative period according to MMS classification of the patients (Figure 4).

\section{Neuroimaging}

Thirty-five patients had intradural-extramedullary, 21 patients had intramedullary and 6 patients had extradural pathologies according to their neuroimaging. Spinal localizations of the pathologies were; cervical in 4 patients, cervicothoracic in 1 patient, thoracic in 32 patients, thoracolumbar in 6 patients and lumbar in 19 patients. Twenty-three patients had preoperative deformity (Table 2).

\section{Surgery}

All of the patients underwent laminoplasty according to the length of the lesions with posterior approach in the prone position. A total of 138 laminae were reconstructed. A maximum of 5 segment laminoplasty was performed. Nine patients underwent 1 segment, 37 patients underwent 2 segments, 10 patients underwent 3 segments, 5 patients underwent 4

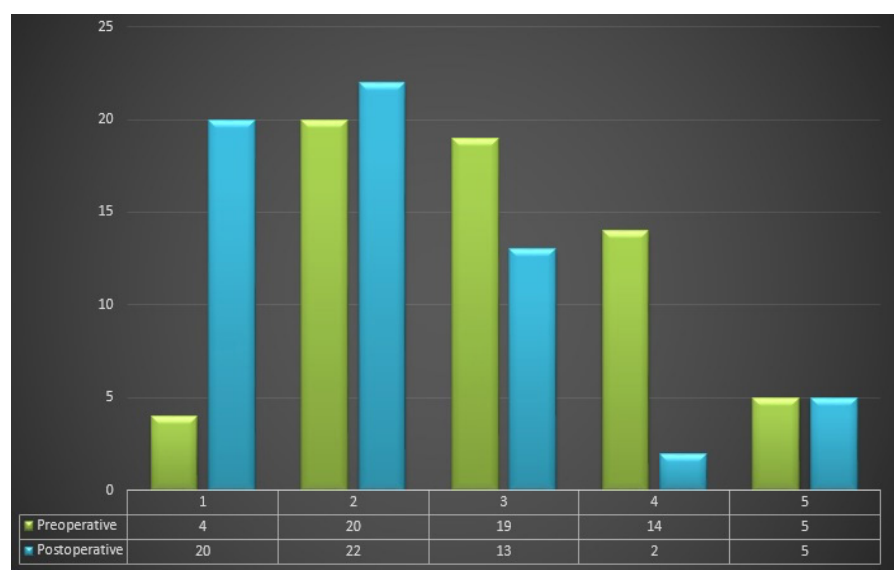

Figure 4. Distribution of the patients' preoperative and postoperative neurological conditions according to Modified McCormick Scale (X axis: Modified McCormick Scale scores, $Y$ axis: number of patients)

Table 1. Demographic data of the patients in the study group

\begin{tabular}{|c|c|c|}
\hline \multicolumn{2}{|l|}{ Characteristics } & Study group $n=62(\%)$ \\
\hline \multicolumn{2}{|l|}{ Age (Mean) } & $44.3 \pm 4.6$ ( $9-80$ years) \\
\hline Gender & Female & 37 (59.6\%) \\
\hline \multicolumn{3}{|l|}{ Pathology } \\
\hline \multirow{5}{*}{ Tumoral } & Schwannoma & $14(22.6 \%)$ \\
\hline & Astrocytoma & $5(8 \%)$ \\
\hline & Lipomatosis & $3(4.8 \%)$ \\
\hline & Metastasis & $2(3.2 \%)$ \\
\hline & Hemangioendothelioma & $1(1.6 \%)$ \\
\hline \multirow{3}{*}{ Non-tumoral } & Cavernous malformation & $3(4.8 \%)$ \\
\hline & Abscess & $3(4.8 \%)$ \\
\hline & Arachnoid cyst & $1(1.6 \%)$ \\
\hline
\end{tabular}

PNET: Primitive neuroectodermal tumor, AVM: Arteriovenous malformation 
segments and 1 patient underwent 5 segment laminoplasty (Table 2). In all patients with intradural pathologies, watertight closure of the duramater was ensured. Valsalva maneuver was performed in order to check cerebrospinal fluid (CSF) leak. The mean duration of hospitalization was 3.6 days (2-64 days interval). The mean follow-up period of the patients was 3 years (1-6 years interval).

\section{Complications}

There were some complications detected in 2 patients. One patient had CSF leak in the long-term period and 1 patient had quadriplegia and respiratory deficiency in the postoperative period (Table 2). Mortality was not developed. The patient who had CSF leak was treated with lumbar subarachnoid drainage. In the postoperative period, quadriplegia and respiratory deficiency were detected in the patient with intramedullary cavernoma in the cervical region. The patient, who was followed in the intensive care unit, was connected to the mechanical ventilator by tracheostomy and the rehabilitation process was started. In terms of the development of postoperative deformity, only 1 patient developed new-onset deformity and 1 patient had progression of previous deformity (Table 2). However, there is no indication of surgery for deformities of these patients.

\section{DISCUSSION}

The technique of cutting and replacing the laminae for surgical treatment of intraspinal pathologies was firstly established by Raimondi et al.(4) in 1976. Hirabayashi et al.(3) defined open-door laminoplasty technique in 1983 and Kurokawa et al.(5) defined French-door laminoplasty technique in 1982. Afterwards, many techniques have been developed to prevent postoperative deformity and adhesion formation in the operation area in spinal cord and cauda equina tumors ${ }^{(6-9)}$. Open-door laminoplasty method is applied by cutting one side of the laminae and pushing the block towards the other side. French-door laminoplasty method is applied by splitting the spinous processes of the vertebrae. Another method which is applied as two-sided cutting of the laminae and then fixation using miniplates is called osteoplastic laminoplasty. We applied osteoplastic laminoplasty method in the present study.

Spinal column is a dynamic system. A simple biomechanical concept of the spine is as two columns, an anterior and a posterior ones. About $80 \%$ of the axial load is absorbed by anterior column, whereas the remaining $20 \%$ is spread to posterior elements as a shearing force. The posterior column, consisting of laminae and facet joints, works as a chain of articulators. Supraspinous-interspinous ligaments and paraspinal muscles support the posterior column especially in the anterior flexion body positions ${ }^{(1,10)}$. In addition to the preservation of bone structures with the application of laminoplasty, it is also aimed to ensure the continuity of the posterior supraspinous and interspinous ligaments and to provide the re-adhesion surfaces of the paraspinal muscles.

Laminectomy is the most widely used surgical method to reveal the spinal canal. However, it has also been reported that laminectomy has very serious disadvantages such as spinal

Table 2. Neuroimaging and surgical characteristics of the patients

\begin{tabular}{|c|c|c|}
\hline Characteristics & & Study group $n=62(\%)$ \\
\hline \multirow{5}{*}{ Localization } & Cervical & $4(6.5 \%)$ \\
\hline & Cervicothoracic & $1(1.6 \%)$ \\
\hline & Thoracic & $32(51.6 \%)$ \\
\hline & Thoracolumbar & $6(9.6 \%)$ \\
\hline & Lumbar & $19(30.7 \%)$ \\
\hline \multirow{3}{*}{ Association with duramater and medulla } & Intramedullary & $21(33.9 \%)$ \\
\hline & Intradural extramedullary & 35 (56.5\%) \\
\hline & Extradural & $6(9.6 \%)$ \\
\hline \multirow{2}{*}{ Preoperative deformity } & + & $23(37 \%)$ \\
\hline & - & $39(63 \%)$ \\
\hline \multirow{5}{*}{ Number of laminoplasty segments } & 1 & $9(14.6 \%)$ \\
\hline & 2 & $37(59.8)$ \\
\hline & 3 & $10(16 \%)$ \\
\hline & 4 & $5(8 \%)$ \\
\hline & 5 & $1(1.6 \%)$ \\
\hline \multirow{2}{*}{ Postoperative deformity } & New-onset & $1(1.6 \%)$ \\
\hline & Worsening & $1(1.6 \%)$ \\
\hline \multirow{2}{*}{ Complications } & CSF leak & $1(1.6 \%)$ \\
\hline & Quadriplegia & $1(1.6 \%)$ \\
\hline
\end{tabular}

CSF: Cerebrospinal fluid 
deformity, instability, acceleration of spondylotic changes, epidural fibrosis and formation of spinal cord and nerve root compression due to laminectomy membrane formation ${ }^{(2,11-15)}$. Laminoplasty provides significant advantages, especially in pediatric patients, avoiding such complications when applied to intraspinal lesions.

The incidence of deformities after laminectomies for spinal cord tumors has been found $10 \%$ in adult patients and $22-100 \%$ in pediatric patients in the literature ${ }^{(13-19)}$. In the study including 55 pediatric patients, patients underwent laminectomy for intramedullary spinal cord tumors and the rate of new deformities was found to be $16 \%$. Operations extending beyond 4 spinal segments and presence of deformity before the operation were defined as the main risk factors ${ }^{(20)}$. In the study performed by Liu et al. ${ }^{(21)}$, spinal instrumentation had to be added in a second session in the patients who underwent surgery extending beyond 3 spinal segments. In the literature, risk factors for postlaminectomy deformities has been defined as age, preoperative deformity, intramedullary tumors, preoperative radiotherapy treatment, increased laminectomy segments, lateral extension and destruction of facets during surgery ${ }^{(2,14,20)}$.

There are studies comparing laminoplasty and laminectomy in the literature in terms of postoperative deformity development ${ }^{(2,18,19,22)}$. In the study performed by McGirt et al. ${ }^{(19)}$, no significant difference was found between laminoplasty and laminectomy in terms of early postoperative deformity. Likewise, Ratliff and Cooper ${ }^{(22)}$ presented no significant difference between the two methods. However, there are studies in the literature that have argued that in all age groups, especially in pediatric patients, the laminoplasty method reduces postoperative deformity development and the need for stabilization in a second session ${ }^{(1,2,9,18,23,24)}$. In the study performed by Montano et al.(2), laminectomy and laminoplasty methods were applied and compared in 43 patients. None of the patients who underwent laminoplasty, developed a new deformity and the rate of deterioration in deformity was found to be lower in the laminoplasty group than in the laminectomy group (2).

CSF leak is another important complication that develops after the resection of the mass lesions in the spinal canal. Especially in patients who underwent laminectomy, the risk of CSF leak increases despite the watertight closure of the dura in these patients due to the destruction of the normal anatomical plan, the excision of one of the barriers and the adhesions to the duramater that may occur in the postoperative period. It is also aimed to decrease the rate of CSF leak by laminoplasty application. Normally, CSF leak rates after laminectomy were presented in the range of $5.3-17.4 \%$ in the literature ${ }^{(2,20,25)}$. Montano et al. ${ }^{(2)}$ presented that CSF leak was not detected in any of the patients who underwent laminoplasty. In the present study, only 1 patient had CSF leak and the rate of CSF leak was detected as $1.6 \%$.
It is known that excessive scar tissue developing after surgery in laminectomy patients is one of the most important factors causing low back pain ${ }^{(1,26)}$. Epidural fibrosis can extend to the neural canal and cause adhesions to the duramater and nerve roots. As a result of this, low back pain and radiculopathy can occur due to traction of the neural structures ${ }^{(1,26)}$. To prevent this, vertebral lamina is the most effective, natural and safe mechanical barrier. Laminoplasty is effective against this complication by preserving the vertebral laminae $e^{(1,2,23)}$. Laminoplasty is also an advantages technique in recurrence surgeries that preserves the anatomical landmarks, provides the easy dissection and reduces the risk of injury to the neural structures ${ }^{(1,2,9)}$.

Despite all these advantages, there are some cases where laminoplasty is not sufficient. The most important of these situations is to consider postoperative deformity in patients with large tumors including long segments, especially above 5 segments. In addition, instrumentation should be considered in surgeries where facet joints cannot be preserved. Laminae should not be reused for laminoplasty in cases with the tumoral invasion of the laminae.

\section{Study Limitations}

There are certain limitations of the present study. The most important limitation was the retrospective nature of the study. The absence of a laminectomy cohort in which we can compare the laminoplasty group is another important limitation. The patient group was not classified as pediatric and adult, and a study group of a total of 62 patients was composed.

\section{CONCLUSION}

Laminoplasty technique has many advantages in the light of the present study and the previous researches in the literature. The most important advantages of laminoplasty technique are as follows; reconstruction of the spinal canal, reduction of the spinal deformity and instability, obtaining better cosmetic results, prevention of epidural fibrosis and adhesions, facilitation of repetitive surgeries and supporting the functions of paraspinal muscles. Laminoplasty is a noticeable technique with the low complication rates and high patient-comfort in the postoperative period.

\section{Ethics}

Ethics Committee Approval: Ethics committee approval was received from Çukurova University Non-Interventional Scientific Research Ethics Committee (11.06.2021-112).

Informed Consent: Retrospective study.

\section{Authorship Contributions}

Surgical and Medical Practices: K.O., A.G., Concept: K.O., A.G., Design: K.O., A.G., Data Collection or Processing: E.G., K.M.O., N.E.C., Data analysis or Interpretation: K.O., U.E., Literature Search: K.O., K.M.O., N.E.C., Writing: K.O., U.E., Critical Revision of Manuscript: K.O., A.G., Final Approval and Accountability: 
K.O., E.G., K.M.O., N.E.C., U.E., A.G., Technical or Material Support: K.O., K.M.O., N.E.C., Supervision: K.O., A.G.

Peer-review: Internally peer-reviewed.

Financial Disclosure: The authors declared that this study received no financial support.

Conflict of Interest: The authors have no conflicts of interest to declare.

\section{REFERENCES}

1. Menku A, Koc RK, Oktem IS, Tucer B, Kurtsoy A. Laminoplasty with miniplates for posterior approach in thoracic and lumbar intraspinal surgery. Turk Neurosurg. 2010;20:27-32.

2. Montano N, Trevisi G, Cioni B, Lucantoni C, Della Pepa GM, Meglio M, et al. The role of laminoplasty in preventing spinal deformity in adult patients submitted to resection of an intradural spinal tumor. Case series and literature review. Clin Neurol Neurosurg. 2014;125:69-74.

3. Hirabayashi K, Watanabe K, Wakano K, Suzuki N, Satomi K, Ishii Y. Expansive open door laminoplasty for cervical spinal stenotic myelopathy. Spine (Phila Pa 1976). 1983;8:693-9.

4. Raimondi AJ, Gutierrez FA, Di Rocco C. Laminotomy and total reconstruction of the posterior spinal arch for spinal canal surgery in childhood. J Neurosurg. 1976;45:555-69.

5. Kurokawa T, Tsuyama N, Tanaka H. Enlargement of spinal canal by sagittal splitting of spinous process. Bessatsu Seikeigeka (Jpn). 1982;2:234-40.

6. Goel A, Deogaonkar M. Thoracic laminoplasty using spino processes - Technical Note. Neurol Med Chir. 1996;36:659-61.

7. Hara M, Takayasu M, Takagi T, Yoshida J. En bloc laminoplasty performed with threadwire saw: Technical note. Neurosurgery. 2001,48:235-9.

8. Kawahara N, Tomita K, Shinya Y, Matsumoto T, Baba H, Fujita T, et al. Recapping T-saw laminoplasty for spinal cord tumors. Spine (Phila Pa 1976). 1999;24:1363-70.

9. Wiedemayer $H$, Sandalcioglu IE, Aalders M, Wiedemayer H, Floerke $\mathrm{M}$, Stolke D. Reconstruction of the laminar roof with miniplates for a posterior approach in intraspinal surgery: technical considerations and critical evaluation of follow-up results. Spine (Phila Pa 1976). 2004;29:E333-42. doi: 10.1097/01.brs.0000134592.07941.5e.

10. Panjabi MM, White AA 3rd. Basic biomechanics of the spine. Neurosurgery. 1980;7:76-93.

11. lida Y, Kataoka O, Sho T, Sumi M, Hirose T, Bessho Y, et al. Postoperative lumbar spinal instability occurring or progressing secondary to laminectomy. Spine (Phila Pa 1976). 1990;15:1186-9.

12. Mayfield FH. Complications of laminectomy. Clin Neurosurg. 1976;23:435-6.
13. Papagelopoulos PJ, Peterson HA, Ebersold MJ, Emmanuel PR, Choudhury SN, Quast LM. Spinal column deformity and instability after lumbar or thoracolumbar laminectomy for intraspinal tumors in children and young adults. Spine (Phila Pa 1976). 1997;22:442-51.

14. Sciubba DM, Chaichana KL, Woodworth GF, McGirt MJ, Gokaslan ZL, Jallo GI. Factors associated with cervical instability requiring fusion after cervical laminectomy for intradural tumor resection. J Neurosurg Spine. 2008;8:413-9.

15. Yeh JS, Sgouros S, Walsh AR, Hockley AD. Spinal sagittal malalignment following surgery for primary intramedullary tumours in children. Pediatr Neurosurg. 2001;35:318-24.

16. de Jonge T, Slullitel H, Dubousset J, Miladi L, Wicart P, Illés T. Lateonset spinal deformities in children treated by laminectomy and radiation therapy for malignant tumors. Eur Spine J. 2005;14:765-71.

17. Lunardi P, Licastro G, Missori P, Ferrante L, Fortuna A. Management of intramedullary tumors in children. Acta Neurochir (Wien). 1993;120:59-65.

18. McGirt MJ, Chaichana KL, Atiba A, Bydon A, Witham TF, Yao KC, et al. Incidence of spinal deformity after resection of intramedullary spinal cord tumors in children who underwent laminectomy compared with laminoplasty. J Neurosurg Pediatr. 2008;1:57-62.

19. McGirt MJ, Garces-Ambrossi GL, Parker SL, Sciubba DM, Bydon A, Wolinksy JP, et al. Short-term progressive spinal deformity following laminoplasty versus laminectomy for resection of intradural spinal tumors: analysis of 238 patients. Neurosurgery. 2010;66:1005-12.

20. Ahmed R, Menezes AH, Awe OO, Mahaney KB, Torner JC, Weinstein $\mathrm{SL}$. Long- term incidence and risk factors for development of spinal deformity following resection of pediatric intramedullary spinal cord tumors. J Neurosurg Pediatr. 2014; 13:613-21.

21. Liu $X Y$, Zheng $Y P, L i$ JM. Laminoplasty for the treatment of extramedullary intradural tumors in the thoracic and lumbar spine: greater than two-year follow-up. Orthop Surg. 2009;1:275-9.

22. Ratliff JK, Cooper PR. Cervical laminoplasty: a critical review. J Neurosurg. 2003;98(Suppl 3):230-8.

23. Iplikcioglu AC, Hatiboglu MA, Ozek E, Dinc C, Erdal M. Surgical removal of spinal mass lesions with open door laminoplasty. Cent Eur Neurosurg. 2010;71:213-8.

24. Zhou D, Nong LM, Gao GM, Jiang YQ, Xu NW. Application of lamina replantation with $\mathrm{ARCH}$ plate fixation in thoracic and lumbar intraspinal tumors. Exp Ther Med. 2013;6:596-600.

25. Guerin P, El Fegoun AB, Obeid I, Gille O, Lelong L, Luc S, et al. Incidental durotomy during spine surgery: incidence, management and complications. A retrospective review. Injury. 2012;43:397-401.

26. Ron NA, David HK, Dan WU, Jie X, Timothy MP, Paul AG. Prevention of postlaminectomy epidural fibrozis using bioelastic materials. Spine (Phila Pa 1976). 2003;28:1659-65. 